\title{
Clinical and surgical evaluation of gynecomastia: tactic and results
}

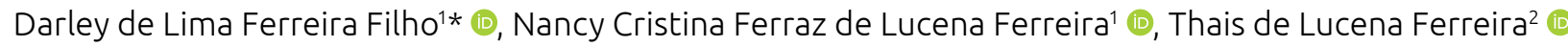

\section{ABSTRACT}

Objectives: To perform an assessment of the clinical and surgical characteristics of gynecomastia as a tactic used and the results obtained in the breast. Methods: A prospective and observational study was carried out in the mastology service of Hospital Barão de Lucena in 40 patients. To determine which factors are associated with the cosmetic outcome, the contingency table was constructed and the $\chi^{2}$ test for independence was applied. In cases in which the assumptions of the $\chi^{2}$ test were violated, Fisher's exact test was applied. Results: Findings showed that most patients were from the metropolitan region of Recife (72.5\%), studied until high school (62.5\%), were aged 10 to 20 (42.5\%), were in gynecomastia grade III (47.5\%), underwent double incision (52.5\%), had no complications (75.0\%), and had a good and excellent cosmetic outcome (75.0\%). The proportion comparison test was significant in all factors evaluated $(p<0.05)$, except for the variable level of education $(p=0.114)$, indicating that the numbers of patients who studied until high school and had higher education are close. The independence test was significant only in the variable complications ( $p<0.001)$, indicating that having complications significantly increases the risk for regular/bad cosmetics. Conclusion: Gynecomastia is a pathology of strong social impact. We observed this after analyzing the epidemiological, clinical, and surgical characteristics of our patients. In patients who underwent surgical treatment and who had no complications, there was a greater degree of satisfaction.

KEYWORDS: man; surgery; estrogen; breasts.

\section{INTRODUCTION}

Gynecomastia was conceptualized by Galeno in the 2nd century $\mathrm{BC}$, who defined it as a fatty accumulation in the man's breast. ${ }^{1}$

Its incidence in the world population is still unknown. However, there are peaks of incidence in newborns between 60 and $90 \%$, presenting a transient development at puberty, beginning at 10 years of age and with a greater peak between 13 and 14. In the adult population, there is more prevalence approximately at 50 years of age, which is maintained until the $8^{\text {th }}$ decade of life., ${ }^{3,4}$ According to Medeiros, there is an incidence of gynecomastia in 8 for every 100,000 individuals in our country. This pathology is responsible for $65 \%$ of benign pathologies in men. ${ }^{5}$

As to pathophysiology, gynecomastia can arise from an imbalance between the concentrations or the effects of free estrogens and androgens. Most gynecomastias have an idiopathic cause, roughly $25 \%$, or persistent gynecomastia at puberty, roughly $25 \%$, but there are pathological causes (cirrhosis and malnutrition= $8 \%$, or primary hypogonadism $=8 \%$ ), less frequently testicular tumors ( $3 \%$ ), secondary hypogonadism ( $2 \%$ ), hyperthyroidism $(1.5 \%)$, or kidney disease (1\%), medications and drugs (10-20\%).

In the treatment of gynecomastia, several available techniques are observed (Figure 1), the choice being based on the degree of pathology, the surgeon's experience, and the adopted tactic.

In the medical field, the treatment of gynecomastia has been little addressed, making it necessary to evaluate the epidemiological and clinical characteristics and the most adopted type of surgery, complications, cosmetic results, and factors related to these results, justifying the present study.

${ }^{1}$ Hospital Barão de Lucena - Recife (PE), Brazil.

${ }^{2}$ Faculdade Pernambucana de Saúde - Recife (PE), Brazil.

*Corresponding author: darleyferreira63@gmail.com

Conflict of interests: nothing to declare.

Received on: 05/20/2020. Accepted on: 07/16/2020. 


\section{METHODS}

This is a prospective and observational study, carried out in the mastology and breast reconstruction service of Hospital Barão de Lucena in 40 patients, between April 2017 and April 2018. Patients were clinically examined at the outpatient clinic, with requests for hormonal tests in some cases, with mammography and ultrasound images in all patients, in which the following variables were analyzed: origin, education level, age, personal history (use of medications), degree of gynecomastia, type of surgery, complications, and cosmetic result.

Patients were assessed using sociodemographic data and background, in addition to factors related to gynecomastia, its treatment and results. A standardized form was used, and data were tabulated in descriptive statistics. For data analysis, a database was built on a Microsoft Excel spreadsheet, which was exported to SPSS software, version 18, in which the analysis was performed. To characterize the personal and clinical profiles, the observed frequencies and percentages of the patients evaluated were calculated, and based on these data, the frequency distribution was constructed. To determine which factors are associated with the cosmetic outcome, the contingency table was constructed and the $\chi^{2}$ test for independence was applied. In cases in which the assumptions of the $\chi^{2}$ test were violated, Fisher's exact test was applied. All conclusions considered a 5\% significance level. Research was approved by the Ethics and Research Committee under number CAAE 63295816.0.0000.5197.

\section{RESULTS}

Table 1 shows the distribution of the personal and clinical profiles of the patients evaluated. Most patients seem to be from the metropolitan region of Recife (72.5\%), studied until high school (62.5\%), are aged from 10 to $20(42.5 \%)$, have no history (75.0\%) for breast cancer, have gynecomastia grade III (47.5\%), underwent double incision (52.5\%), had no complications (75.0\%), and had good or excellent cosmetic outcome (75.0\%). The proportion comparison test was significant in all factors evaluated $(\mathrm{p}<0.05)$, except for the variable education level $(\mathrm{p}=0.114)$.

Table 2 shows the distribution of the cosmetic result according to personal and clinical factors. There is a higher prevalence of regular/poor cosmetic results in the group of patients from outside the metropolitan region of Recife (27.3\%), with higher education (33.3\%), over 50 years old (50.0\%), with personal history (50.0\%), with gynecomastia grade III or IV (50.0\%), having undergone periareolar surgery $(31.2 \%)$ and with complications (20.0\%). Even though a higher prevalence of regular/bad cosmetics was observed in the group of patients with the profile described, the independence test was significant only in the variable complications $(\mathrm{p}<0.001)$, indicating that having complications significantly increases the risk for regular/bad cosmetic, which is about 26 times higher (prevalence ratio=26) than that of the group of patients without complications.

\section{DISCUSSION}

Gynecomastia is a benign disorder, due to a proliferation of ductal tissues, stroma and fat. ${ }^{6.7}$ However, cosmetic changes and physical discomfort in patients cause serious stress and psychological problems, especially in adolescent boys, who avoid taking their shirts off in public places. In our casuistry, most patients were

Table 1. Distribution of clinical and surgical profiles of the studied population $(n=40)$.

\begin{tabular}{|c|c|c|c|}
\hline Factor evaluated & $\mathbf{n}$ & $\%$ & p-value* \\
\hline \multicolumn{4}{|l|}{ Place of origin } \\
\hline MR of Recife & 29 & 72.5 & \multirow{2}{*}{0.004} \\
\hline Outside the MR of Recife & 11 & 27.5 & \\
\hline \multicolumn{4}{|l|}{ Education level } \\
\hline Until high school & 25 & 62.5 & \multirow{2}{*}{0.114} \\
\hline Undergraduate & 15 & 37.5 & \\
\hline \multicolumn{4}{|l|}{ Age range (years old) } \\
\hline 10 to 20 & 17 & 42.5 & \multirow{6}{*}{$<0.001$} \\
\hline 21 to 30 & 9 & 22.5 & \\
\hline 31 to 40 & 5 & 12.5 & \\
\hline 41 to 50 & 1 & 2.5 & \\
\hline 51 to 60 & 5 & 12.5 & \\
\hline Over 60 & 3 & 7.5 & \\
\hline \multicolumn{4}{|l|}{ Medical personal history } \\
\hline No history & 30 & 75.0 & \multirow{3}{*}{$<0.001$} \\
\hline Drugs/alcoholism & 4 & 10.0 & \\
\hline Medications & 6 & 15.0 & \\
\hline \multicolumn{4}{|l|}{ Degree of gynecomastia } \\
\hline Degree I & 10 & 25.0 & \multirow{4}{*}{0.001} \\
\hline Degree II & 10 & 25.0 & \\
\hline Degree III & 19 & 47.5 & \\
\hline Degree IV & 1 & 2.5 & \\
\hline \multicolumn{4}{|l|}{ Type of surgery } \\
\hline Periareolar & 16 & 40.0 & \multirow{4}{*}{$<0.001$} \\
\hline Double incision & 21 & 52.5 & \\
\hline Pitanguy & 2 & 5.0 & \\
\hline Subcutaneous mastectomy & 1 & 2.5 & \\
\hline \multicolumn{4}{|l|}{ Complications } \\
\hline None & 30 & 75.0 & \multirow{4}{*}{$<0.001$} \\
\hline Seroma & 5 & 12.5 & \\
\hline Bruise & 4 & 10.0 & \\
\hline Keloid & 1 & 2.5 & \\
\hline \multicolumn{4}{|l|}{ Cosmetic } \\
\hline Great & 14 & 35.0 & \multirow{4}{*}{0.004} \\
\hline Good & 16 & 40.0 & \\
\hline Regular & 9 & 22.5 & \\
\hline Bad & 1 & 2.5 & \\
\hline
\end{tabular}

${ }^{*} \mathrm{p}$-value of the $\chi^{2}$ test for comparison of ratios; MR: metropolitan region. 
at puberty (43\%). These results are in accordance with the world literature, which shows, the occurrence of 30 to $60 \%$ of gynecomastias in this age group. If the patient has pain or hypersensitivity or feels embarrassed by gynecomastia, the possibility of removing the mammary gland should be suggested. ${ }^{8,9}$

Gynecomastia is a very frequent alteration, which justifies the wide range of publications regarding its treatment. There are many causes of gynecomastia, including an imbalance between estrogens and androgens, although its exact etiology is unknown. ${ }^{10}$

Modern surgical treatment begins with the concern to hide the scar as much as possible, by incisions through the areola or very close to it. ${ }^{11}$ The periareolar incision has an excellent access route for Simon's small type I and II gynecomastias, with discrete scars, but it promotes a small operative field and, if indicated for larger gynecomastias, it may cause technical difficulties and areolopapillary suffering due to excessive tension ${ }^{12-14}$ (Figure 1). For the transareolo-nipple incision or Pitanguy technique, the same considerations are valid (Figure 1).

The R. Sinder zeta incision allows wider access but is still deficient for major gynecomastias. Stewart's submammary incision and/or female glandular resection techniques leave final horizontal and transverse scars, in addition to the periareolar incision, which offers the possibility of proceeding with gland and skin resection in moderate and large hypertrophies, but they are complicated techniques and leave very visible scars (Figure 1).
The double incision periareolar technique (round-block) has been used in our service at Hospital Barão de Lucena for the treatment of grades III and IV gynecomastias. In our material, grades III and IV corresponded to $50 \%$ of the cases, and double incision was performed in $52 \%$ of the patients, unlike what was found in Montiel et al., which had 50\% of the periareolar incisions, because it provides simplicity, insofar as surgeons are familiar with this type of approach in female mammoplasty; safety, by maintaining a wide upper pedicle for the nipple-areolar complex; maintenance and/or correction of the positioning of the nipple-areola complex; symmetry of the nipple-areola complexes, when removing the excess skin in a circular manner; enlargement of the operative field, facilitating and reducing the time of the surgical act and the resection of the excess skin in the surgery with approach in the double incision technique (Figures 2, 3 and 4).

Just like with female mammoplasties, the circular periareolar technique represents an alternative access route in the surgical treatment of large gynecomasties, grades II, III and IV, in which, in addition to excision of the gland, excess skin resection is required. According to Rohrich et al., its classification is based on grades I to IV, in which the volume and degree of ptosis are evaluated. ${ }^{15}$

Scars widening is a frequent complication. Is does not occur due to tension, but to extensive skin resection, as well as the

Table 2. Distribution of the cosmetic aspect according to personal and clinical factors.

\begin{tabular}{|c|c|c|c|c|c|}
\hline \multirow{2}{*}{ Factor evaluated } & \multicolumn{2}{|c|}{ Cosmetic } & \multirow{2}{*}{ p-value } & \multirow{2}{*}{ PR } & \multirow{2}{*}{$95 \% \mathrm{Cl}$} \\
\hline & Regular/Bad (\%) & Great/Good (\%) & & & \\
\hline \multicolumn{6}{|l|}{ Place of origin } \\
\hline MR of Recife & $7(24.1)$ & $22(75.9)$ & \multirow{2}{*}{$1.000 *$} & 1.00 & - \\
\hline Outside the MR of Recife & $3(27.3)$ & $8(72.7)$ & & 1.13 & $0.35-3.61$ \\
\hline \multicolumn{6}{|l|}{ Education level } \\
\hline Until high school & $5(20.0)$ & $20(80.0)$ & \multirow{2}{*}{$0.457^{*}$} & 1.00 & - \\
\hline Undergraduate & $5(33.3)$ & $10(66.7)$ & & 1.67 & $0.58-4.82$ \\
\hline \multicolumn{6}{|l|}{ Age range (years old) } \\
\hline Until 30 & $5(19.2)$ & $21(80.8)$ & \multirow{3}{*}{$0.236^{*}$} & 1.15 & $0.16-8.15$ \\
\hline 31 to 50 & $1(16.7)$ & $5(83.3)$ & & 1.00 & - \\
\hline Over 50 & $4(50.0)$ & $4(50.0)$ & & 3.00 & $0.44-20.44$ \\
\hline \multicolumn{6}{|c|}{ Personal history with medicines or drugs } \\
\hline Absent & $5(16.7)$ & $25(83.3)$ & \multirow{2}{*}{$0.085^{*}$} & 1.00 & - \\
\hline Present & $5(50.0)$ & $5(50.0)$ & & 3.00 & $1.09-8.25$ \\
\hline \multicolumn{6}{|l|}{ Degree of gynecomastia } \\
\hline Degrees I and II & $4(20.0)$ & $16(80.0)$ & \multirow{2}{*}{$0.465^{* *}$} & 1.00 & - \\
\hline Degrees III and IV & $6(30.0)$ & $14(70.0)$ & & 1.50 & $0.50-4.52$ \\
\hline \multicolumn{6}{|l|}{ Type of surgery } \\
\hline Periareolar & $5(31.2)$ & $11(68.8)$ & \multirow{2}{*}{$0.482^{*}$} & 1.50 & $0.52-4.36$ \\
\hline Another & $5(20.8)$ & $19(79.2)$ & & 1.00 & - \\
\hline \multicolumn{6}{|l|}{ Complications } \\
\hline Absent & $1(3.3)$ & $29(96.7)$ & \multirow{2}{*}{$<0.001^{*}$} & 1.00 & - \\
\hline Present & $9(90.0)$ & $1(10.0)$ & & 27.00 & $3.89-187.53$ \\
\hline
\end{tabular}

PR: prevalence ratio; Cl: confidence interval for PR; * $\mathrm{p}$-value of Fisher's exact test; ** $\mathrm{p}$-value of the $\chi^{2}$ test for independence; MR: metropolitan region. 
formation of hematoma and seroma represented $20 \%$ of our complications in the post-surgical period. Lapid et al. demonstrated in their casuistry of 20 years of experience that hematoma followed by seroma are the most common complications. ${ }^{16}$
The independence test was significant only in the postoperative complications variable $(\mathrm{p}<0.001)$, indicating that these complicating patients significantly increased the risk for unsatisfactory cosmetic results. Most of our patients had a degree
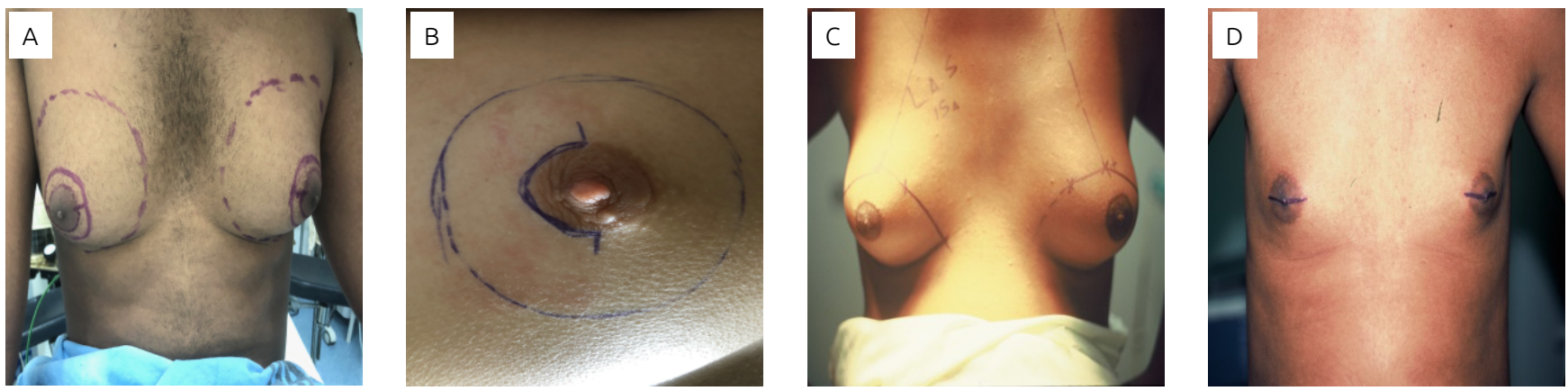

E

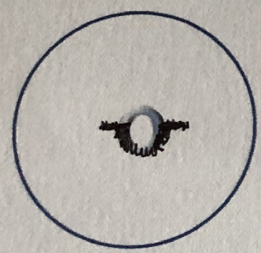

WEBSTER

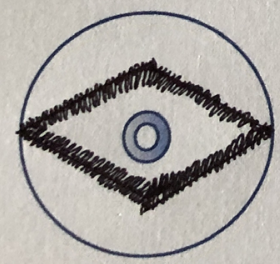

STEWART

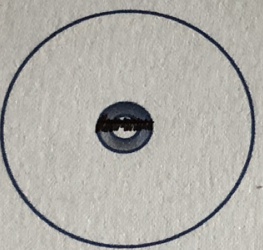

PITANGY

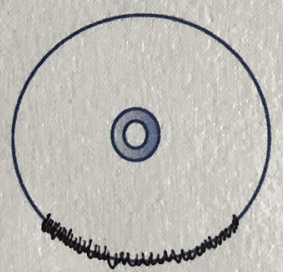

SUBMAMARIA

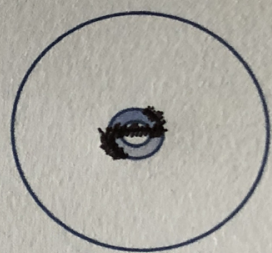

SINDER

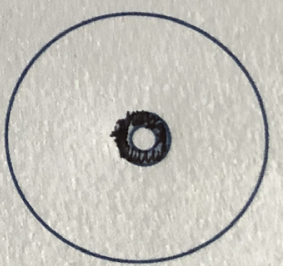

PERIAREOLAR

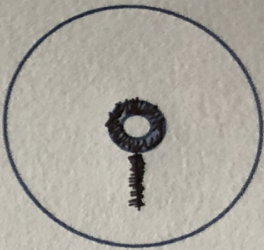

VERTICAL

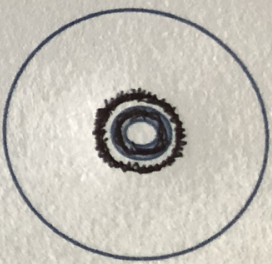

DUPLO-CIRCULO

Figure 1. Some incisions that can be used in the correction of gynecomastia (double incision [round-block], Webster, periareolar, mastoplasty using the Pitanguy technique, transareolopapillary, Sinder, vertical, and Stewart).
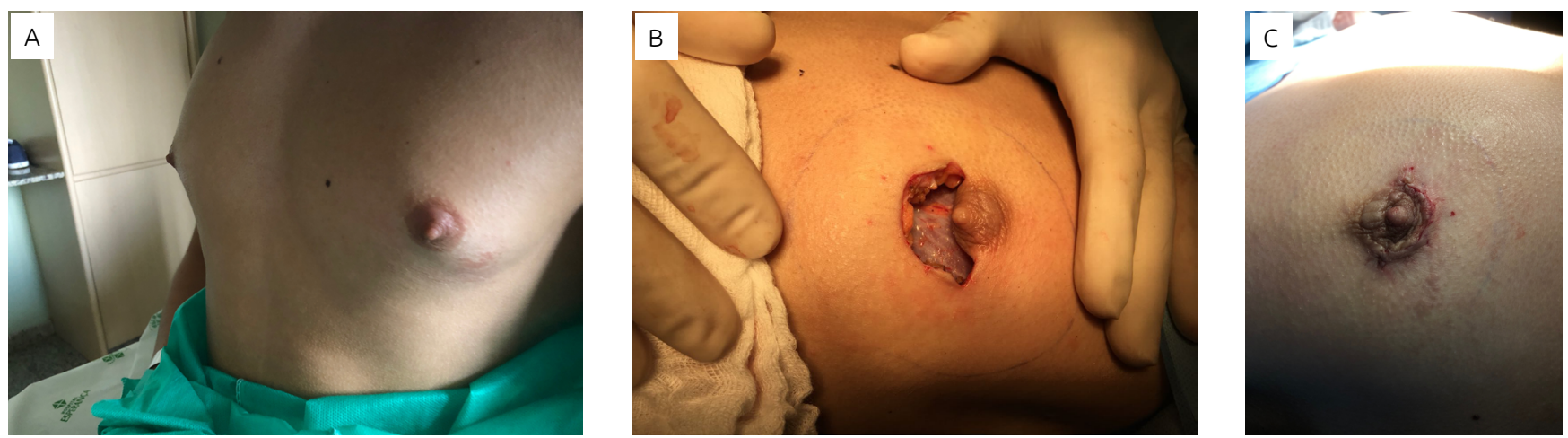

Figure 2. Degree I gynecomastia. Pre and postoperative (Webster's periareolar technique). 

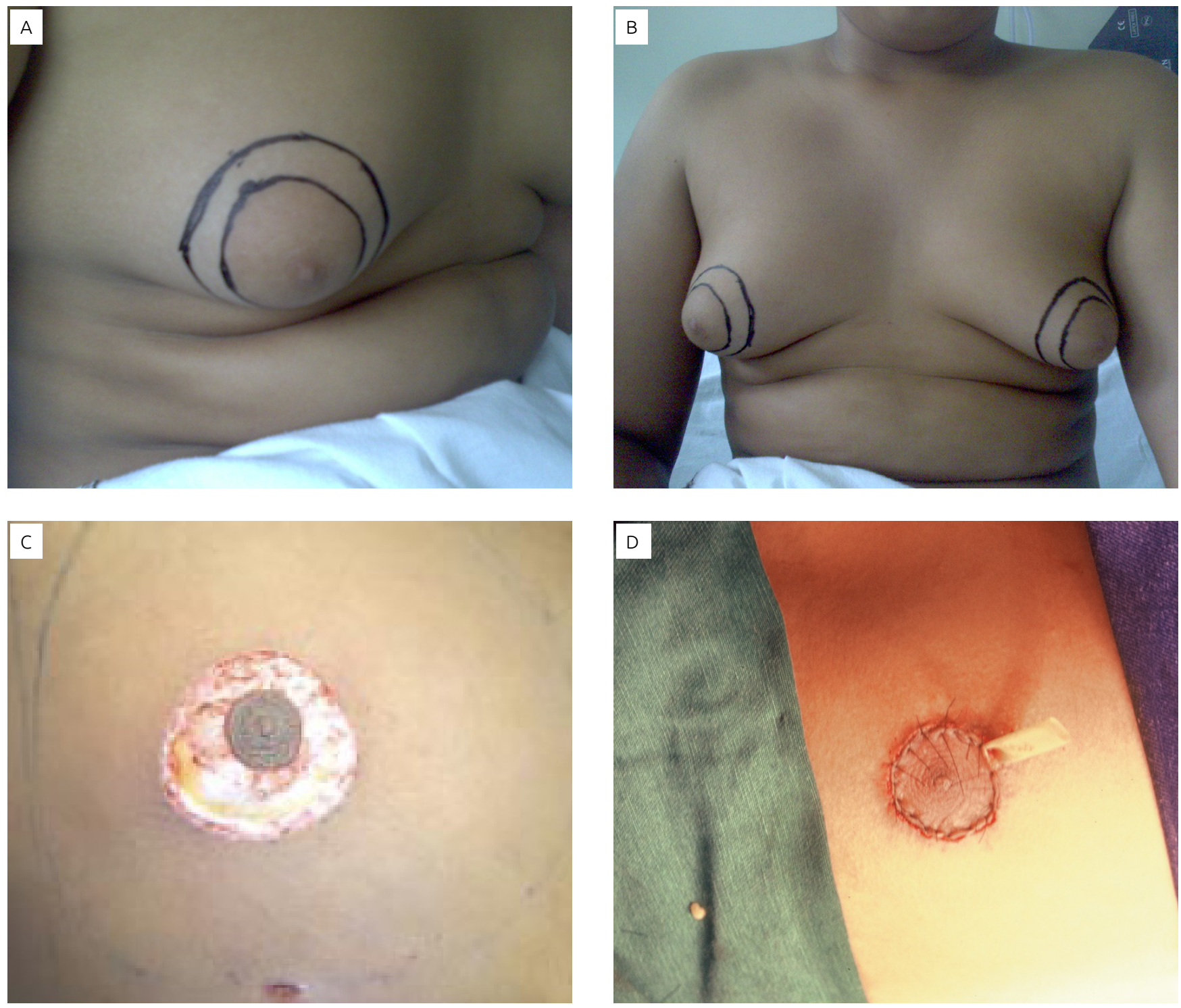

Figure 3. Degree II/III gynecomastia. Pre and postoperative (double incision).
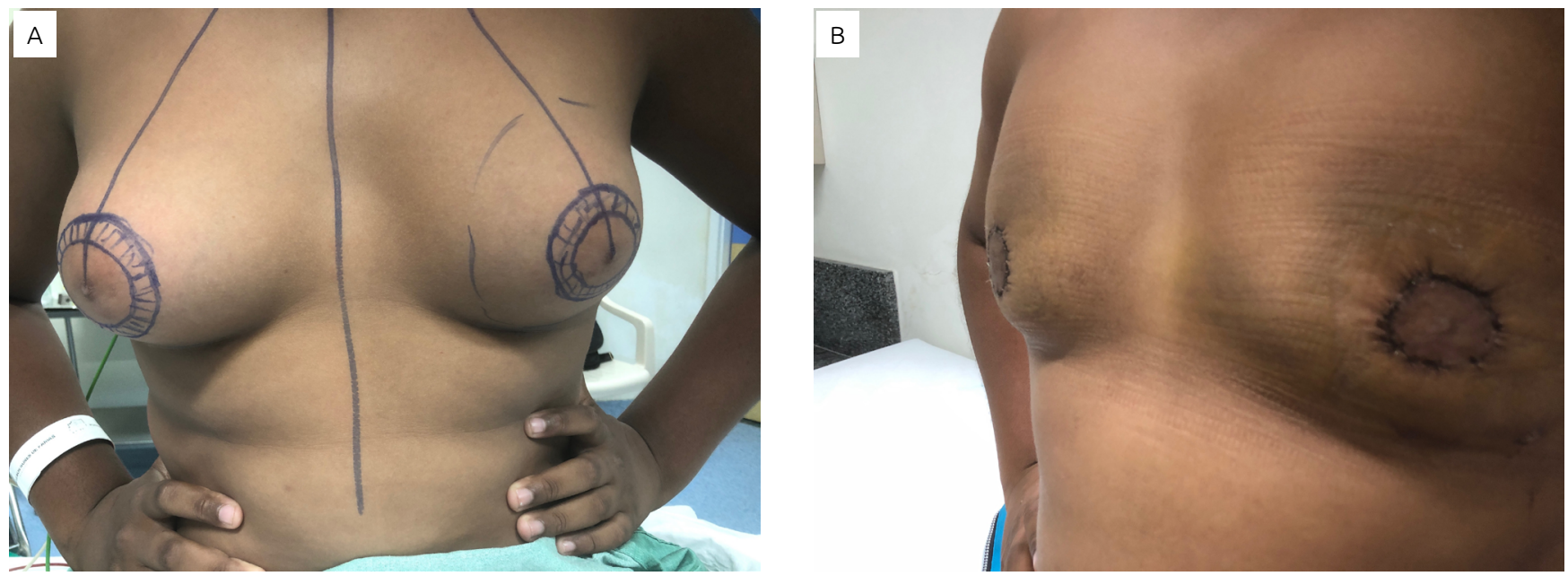

Figure 4. Degree III/IV gynecomastia. Pre and postoperative (double incision). 
of gynecomastia III/IV (around 50\%), with a higher probability of complications. In our casuistry, the degree of satisfaction was $75 \%$. Unlike our results, Gabra et al., in a study with 39 adolescents, found a satisfactory result in $88 \%$ of patients, only $12 \%$ reported dissatisfaction. ${ }^{17}$ Colombo-Benkmann et al. also observed, in their analysis of 100 patients, that the degree of gynecomastia II and III and the type of incision are associated with specific sequelae. The degree of patient satisfaction was $86 \% .^{18}$

None of our patients underwent treatment with medication to reduce breast volume, given that the Unified Health System (SUS) only releases this type of medication for cancer patients. Besides that, our patients had a large breast volume. Testosterone was used only in hypogonadism. Dihydrotestosterone was effective in some uncontrolled studies. Danazol can bring some benefit, but it has a high cost. Tamoxifen was effective in several studies, at a dose of $20 \mathrm{mg} /$ day for three months, similar to raloxifene. Regarding aromatase inhibitors, there are few studies, although they have shown a positive response with anastrozole $1 \mathrm{mg}{ }^{18-22}$

\section{CONCLUSION}

Gynecomastia is a pathology that causes great psychosocial impact, and its surgical treatment can bring satisfaction and better adaptation of young patients to society. Patients who do not have postoperative complications are those who have the highest degree of satisfaction.

\section{AUTHORS' CONTRIBUTION}

D.F.: conceptualization, funding acquisition, investigation, methodology, investigation, project administration, supervision, validation, visualization, writing - review \& editing.

N.F.: investigation, validation, visualization, writing - review \& editing.

N.F..: data curation, formal analysis, investigation, writing original draft.

T.F.: data curation, formal analysis, investigation, writing original draft.

D.F.: conceptualization, data curation, formal analysis, investigation, visualization, writing — original draft, writing — review \& editing.

\section{REFERENCES}

1. Montiel-Jarquin AJ, Romero-Figueiroa MS, EtchegarayMorales I, Solis-Mendonza HA. Treatment for gynecomastia: differences for external and inferior periareolar incision for subdermal mastectomy. Rev Chil Cir. 2017;69(1):10-5. http:// dx.doi.org/10.4067/S0718-40262017000100005

2. Narula HS, Carlson HE. Gynecomastia: pathophysiology, diagnosis and treatment. Nt Rev Endocrinol. 2014;10(11):68498. https://doi.org/10.1038/nrendo.2014.139

3. Montana Padilla, GS, Eugenio Camargo G, Sánchez Capacho N, Diaz Matallana M, Reyes Mendoza JG. Knowledge and practices of gynecomastia of non-specialist's doctors. Rev Investig Solid Univ Boyacá. 2019;6(1):34-54. https://doi. org $/ 10.24267 / 23897325.283$

4. Leung AKC, Leung AAC. Gynecomastia in infants, children, and adolescents. Recent Pat Endocr Metab Immune Drug Discov. 2016;10(2):127-37. https://doi.org/10.2174/18722148116 66170301124033

5. Medeiros MM. Abordagem cirúrgica para tratamento de gynecomastia conforme sua classificação. Rev Bras Cir Plást. 2012;27(2):277-82. https://doi.org/10.1590/S198351752012000200018

6. Wilson JD, Aiman J, MacDonald PC. The pathogenesis of gynecomastia. Adv Intern Med. 1980;29;1-32.

7. Braunstein GD. Gynecomastia. N Engl J Med. 1993;328:490-5. https://doi.org/10.1056/NEJM199302183280708

8. Lapid O, Jolink F. Surgical management of gynecomastia: 20 years experience. Scand J Surg. 2014;103(1):41-5. https://doi. org $/ 10.1177 / 1457496913496359$
9. Ma NS, Geffner ME. Gynecomastia in prepuberal and puberal men. Curr Opin Ped. 2008;20(4):465-70. https://doi.org/10.1097/ MOP.0b013e328305e415

10. Karp NS. Gynecomastia. In: Thorne CH, Beasley RW, Aston SJ, Gurtner GC, Spear SL, editors. Grabb and Smith's Plastic Surgery. 6. ed. Filadélfia: Wolters Kluwer Lippincott Williams \& Wilkins; 2006. p. 616-20.

11. Hammond DC. Surgical correction of gynecomastia. Plast Reconstr Surg. 2009;124(1 Supl.):6le-8e. https://doi. org/10.1097/prs.0b013e3181aa2dc7

12. Waltho D, Hatchell A, Thoma A. Gynecomastia classification for surgical management: A Systematic Review and Novela ClassificationSystem.PlastReconstrSurg.2017;139(3):638e-48e. https://doi.org/10.1097/prs.0000000000003059

13. Webster JP. Mastectomy for Gynecomastia through semicircular intra-areolar incisions. Ann Surg. 1946;124(3):557-75.

14. Simon BE, Hoffman S, Kahn S. Classification and surgical correction of Gynecomastia. Plast Reconst Surg. 1973;51(1):48-52.

15. Rohrich RJ, Ha RY, Kenkel JM, Adams Jr. WP. Classification and Management of Gynecomastia: difining the role of ultrasoundassisted liposuction. Plast Reconst Surg. 2003;111(2):909-23. https://doi.org/10.1097/01.prs.0000042146.40379.25

16. Gruntmanis U, Braunstein GD. Treatment of Gynecomastia. Curr Opin Invest Drug. 2001;2(5):643-9.

17. Gabra HO, Morabito A, Bianchi A, Bowen J. Gynecomastia in the adolescent: A Surgically Relevant Condition. Eur J Pediatr Surg Feb. 2004;14(1):3-6. https://doi.org/10.1055/s-2004-815772 
18. Colombo-Benkmann M, Buse B, Stern J, Herfarth C. Indications for and results of surgical therapy for male gynecomastia. Am J Surg. 1999;178(1):60-3. https://doi. org/10.1016/s0002-9610(99)00108-7

19. Lawrence SE, Faught KA, Vethamuthu J, Lawson ML. Beneficial effects of raloxifene and tamoxifen in the treatment of pubertal gynecomastia. J Pediatr. 2004;145(1):71-6. https:// doi.org/10.1016/j.jpeds.2004.03.057

20. Hanavadi S, Banerjee D, Monypenny IJ, Mansel RE. The role of tamoxifen in the management of gynecomastia.
Breast. 2006;15(2):276-80. https://doi.org/10.1016/j. breast.2005.04.007

21. Zachmann M, Eiholzer U, Muritano M, Werder EA, Manella B. Treatment of pubertal gynaecomastia with testolactone. Acta Endocrinol Suppl (Copenh). 1986;279:218-26. https://doi. org/10.1530/acta.0.112s218

22. Plourde PV, Reiter EO, Jou HC, Desrochers PE, Rubin SD, Bercu $\mathrm{BB}$, et al. Safety and efficacy of anastrozole for the treatment of pubertal gynecomastia: a randomized, double-blind, placebocontrolled trial. J Clin Endocrinol Metab. 2004;89(9):4428-33. https://doi.org/10.1210/jc.2004-0082 